\title{
Habitat preferences of bats in anthropogenically altered, mosaic landscapes of northern Poland
}

\author{
Mateusz Ciechanowski
}

Received: 15 September 2014 /Revised: 16 February 2015 / Accepted: 17 February 2015 /Published online: 3 March 2015

(C) The Author(s) 2015. This article is published with open access at Springerlink.com

\begin{abstract}
Few studies refer to the large-scale habitat preferences of bat assemblages in temperate mainland Europe. The study aimed at habitat associations of bats in the postglacial lakelands of northern Poland. Sixty-nine walking transects were divided into sections belonging to 36 habitat classes. Broadband ultrasound detectors were applied to record bat echolocation calls, identified to the species level by spectral analysis. Selection or avoidance of habitat categories was tested using $\mathrm{Z}$ statistic with a Bonferroni adjustment, and niche breadth was estimated by calculating Levin's formula and niche overlap-Pianka index. All bats (except Eptesicus serotinus) selected water bodies. They avoided arable land, coniferous and mixed forests, their edges and suburbs. Nyctalus noctula was the most eurytopic species, using most habitats in proportion to their availability. E. serotinus selected villages and roads in coniferous forests. Narrower habitat niches were occupied by morphologically similar pipistrelles. Pipistrellus pipistrellus preferred tree lines, Pipistrellus nathusii avoided tree lines and villages, and Pipistrellus pygmaeus preferred roads in deciduous forests but avoided tree lines. The most stenotopic Myotis sp. avoided roads in mixed and coniferous forests, tree lines and built-up areas. Most species strongly overlapped in habitat niches, and thus, their resource partitioning was probably based on using different hunting tactics. P. pygmaeus, although considered a sibling species of $P$. pipistrellus, overlapped in habitat niche much more with $P$. nathusii. In the latter case, resource partitioning may result from larger differences in body size
\end{abstract}

Communicated by C. Gortázar

M. Ciechanowski $(\bowtie)$

Department of Vertebrate Ecology and Zoology, Faculty of Biology, University of Gdańsk, ul. Wita Stwosza 59, 80-308 Gdańsk, Poland e-mail: matciech@kki.net.pl and frequency of echolocation calls. The importance of water bodies for bats was higher than in Western Europe, and importance of woodland was lower, presumably due to much higher limnicity. The results provide a base for regionspecific landscape planning guidelines, applicable to bat conservation.

Keywords Chiroptera $\cdot$ Vespertilionidae $\cdot$ Temperate zone · Habitat use $\cdot$ Niche breadth $\cdot$ Resource partitioning

\section{Introduction}

Insectivorous bats of the temperate zone use excessively large home ranges when compared to other small mammals of similar body size (Robinson and Stebbings 1997; Davidson-Watts et al. 2006; Mackie and Racey 2007; Flaquer et al. 2009). This peculiarity results from their ability for active flight that allows them to move across large distances between patches of optimal habitats. Bats are 'multi-habitat' animals, using a number of different habitats that provide the functions of daily roosts, breeding sites, winter roosts, commuting routes, drinking and foraging sites. Despite significant plasticity in the choice of roost and foraging sites, as well as a broad spectrum of diet (Vaughan 1997), these mammals prefer some particular habitats during night-time activity (Vaughan et al. 1997a). These include some prominent structures that appear only after heavy transformation of the landscape by humans, most notably tree lines (Verboom and Huitema 1997). Bats choose patches of landscape differing in land use, human modification, vegetation, geomorphology and underlying geology that all determine the productivity of an ecosystem and prey abundance (Threfall et al. 2012a, b). 
Detailed knowledge of the habitat preferences and space use of particular species in different parts of its distribution range provides a necessary base for rational conservation planning on a wider geographic scale (Sanderson et al. 2002). Thus, abundant studies (e.g. Walsh and Harris 1996; Vaughan et al. 1997a; Russ and Montgomery 2002) on bat habitat preferences conducted in Western Europe, which has the heaviest anthropogenic transformation of the landscape and is strongly influenced by the oceanic climate, are not sufficient for establishing the conservation needs for central and eastern parts of the continent. Differences in the diet of noctule Nyctalus noctula between Great Britain (significant share of terrestrial insects - Jones 1995) and Latvia (almost exclusively aquatic insects-Rydell and Petersons 1998) appear to confirm this hypothesis, and similar differences can be expected in habitat preferences. Moreover, regional differences in species' habitat use might be modified by the presence or absence of potential competitors and the resulting differences in patterns of resource partitioning. Several studies focused on the habitat use of two sibling bat species, Pipistrellus pipistrellus and P. pygmaeus in Western Europe (Vaughan et al. 1997a; Russ and Montgomery 2002; Davidson-Watts et al. 2006; Nichols and Racey 2006; Sattler et al. 2007). However, they rarely included the third member of the Pipistrellus genus, Pipistrellus nathusii, i.e. the common and locally dominant bat species in the Polish lowlands (Sachanowicz et al. 2006); the notable exceptions were an automatic acoustic survey of German forests (Jung et al. 2012) and a robust, landscape-scale distribution modelling (Kusch and Schmitz 2013).

The aim of this study was to investigate the habitat preferences of bats in the different landscapes of postglacial lakelands and coastal areas of the Gdańsk Pomerania region which has undergone multifactorial anthropogenic transformation, including agriculture, forestry, settlements and infrastructure. I expected that (1) habitats considered to be the most productive (water bodies, broadleaved forests) will be selected along with habitats of higher structural complexity (forests in general, tree lines) than their surroundings, (2) the open areas (arable land, meadows) will be avoided, and (3) morphologically similar Pipistrellus species will reveal pattern of resource partitioning by selecting different habitats and low niche overlap.

\section{Materials and methods}

\section{Study area}

The study area overlaps with the Gdańsk Pomerania region, northern Poland (Fig. 1), according to the definition accepted for geobotanical survey (Markowski and Buliński 2004), slightly broadened for the needs of bat surveys in the Gdańsk region (bordered by meridians $16^{\circ} 33^{\prime} \mathrm{E}$ and $20^{\circ} 13^{\prime}$ E, parallel $53^{\circ} 27^{\prime} \mathrm{N}$, and Baltic Sea coastline, extending to $54^{\circ} 49^{\prime} \mathrm{N}$ ). The sea coast is usually built by sand dunes; one brackish lagoon and a few coastal lakes are separated from the sea by sand bars. The largest Polish river, Vistula, discharges here into the Baltic, forming a flat delta built by alluvial sediments, recently drained by a network of canals and ditches, and maintaining a uniform block of farmland. Most of the region is covered by either postglacial moraines with a strongly differentiated relief (hills up to $328 \mathrm{~m}$ a.s.l), or flat, sandy, outwash plains. The latter two landscapes not only are rich in postglacial lakes but also contain an extensive network of smaller rivers; inland surface waters cover $\sim 5 \%$ of the region. Large blocks of managed forests $(\sim 36 \%$, dominated by Scotch pine Pinus sylvestris, beech Fagus sylvatica, spruce Picea abies, birch Betula pendula and oak Quercus robur) form a mosaic with agricultural landscape $(\sim 50 \%)$ and human settlements $(\sim 6 \%)$.

\section{Selection of transects and habitat classification}

The study area covers 347 UTM $10 \times 10-\mathrm{km}$ squares. Among them, 100 squares were chosen at random (Fig. 1), using a pseudo-random number generator based on discrete probability distribution and a software written in VBA language by AZB Analysis \& Software (Gdańsk, Poland). The season (year of the study 1-3) was included as a factor in the randomization procedure. Due to logistical problems, equipment failure and prolonged periods of bad weather, only 69 squares were surveyed. In every square, a linear transect, 2109 $5246 \mathrm{~m}$ long (mean $3483.9 \mathrm{~m}, \mathrm{SD} \pm 576.2$ ), was set up based on a topographic map 1:10,000. The total length of all transects amounted to $240,389 \mathrm{~m}$. Every transect crossed as many different habitat classes as possible, distinguished through criteria given by Walsh and Harris (1996), Vaughan et al. (1997a) and Russ and Montgomery (2002) but modified due to the landscape and geobotanical specificity of the Gdańsk Pomerania region. In total, 36 habitat classes were distinguished (Table 1). Before evening recordings, the transect was walked in daylight and divided into sections attributed to particular habitat classes. Data on the length of each transect, as well as the coordinates of nodal points, were established using GPS Garmin receiver (models 76 or eTrex), downloaded to computer using MapSource software and visualized on digital versions of topographic maps in Quantum GIS 1.6.0 software. The latter allowed measurement of the length of every section of transect, and the total length of routes walked in every distinguished habitat class.

\section{Recording of bat calls}

Recording of bat activity on every transect in 2009-2010 was conducted with a Pettersson D-1000X ultrasound detector. Bat calls were transformed to audible sound by the frequency division mode, the high frequency recording mode was activated manually and original untransformed ultrasounds were 
Fig. 1 Location of the study area and UTM squares selected for bat recordings

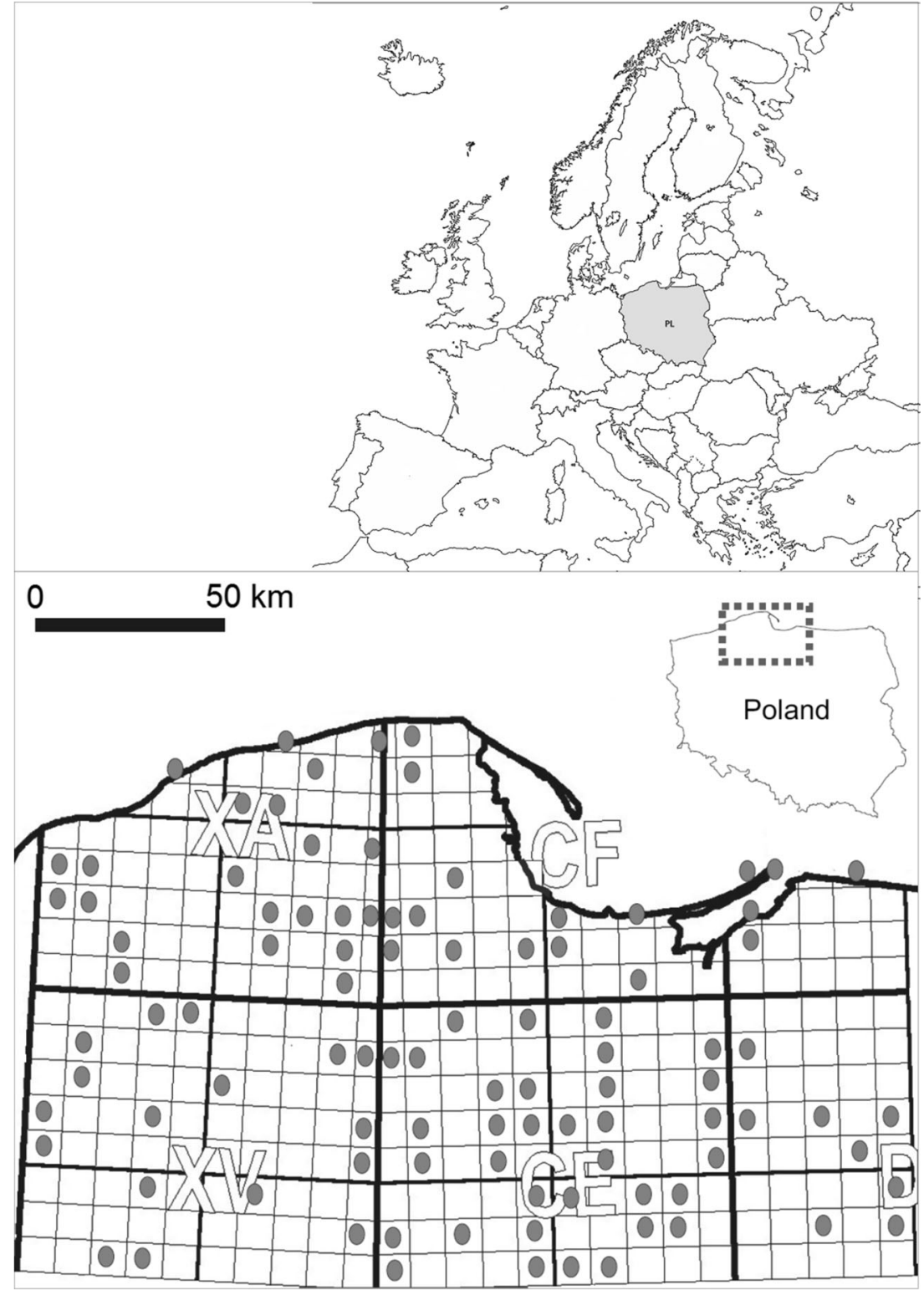

recorded at a sampling frequency of $400 \mathrm{kHz}$ with $3 \mathrm{~s}$ of pretrigger time and saved (also manually) as a mono .wav file on an internal Compact Flash memory card after the last calls of the sequence. In 2008, bat calls were recorded with a Pettersson D-980 ultrasound detector and by audio digital recorder Boss MICRO BR, Roland, Japan (on a Secure Digital memory card). In the latter situation, sound transformed by the frequency division mode was recorded constantly in the left channel of a stereo .wav file, but when bat calls were heard, the time expansion mode was triggered manually, and 3-s long sample, time expanded $\times 10$, was recorded in the right channel (at a sampling frequency of $44.1 \mathrm{kHz}$ ). Field works were conducted exclusively from June to July, i.e. during late pregnancy and lactation of temperate zone bats, when the maximum bat activity appeared in the first $2-3 \mathrm{~h}$ after sunset. Every selected $10-\mathrm{km}$ square was visited only once during the whole period of study (2008-2010) to avoid pseudoreplication, and only one square was sampled during any single night. Recordings were only conducted during rainless nights with windspeed $<6 \mathrm{~m} / \mathrm{s}$. Every transect was walked on foot twice during the evening. The first walk started $30 \mathrm{~min}$ after sunset (time of sunset established for coordinates of the centre of the UTM square) and lasted 40-50 min, while the second walk started immediately after the end of the first. Such protocol allowed recording of all bat species occurring in the study area that may differ in time of evening emergence.

Analysis of bat calls

After recording, WAV sound files were downloaded to personal computer and analysed using BatSound 3.31 Software (Pettersson Elektronik AB, Sweden). A sequence of at least 
Table 1 Description of habitat classes

\begin{tabular}{|c|c|c|c|}
\hline Habitat group & Habitat class & Abbreviation & Definition \\
\hline \multirow[t]{15}{*}{ Forests } & Broadleaved forest & $\mathrm{BF}$ & $\begin{array}{l}\text { Interior of an intact patch of predominantly broadleaved } t \\
\text { rees greater than } 4 \mathrm{~m} \text { in height. }\end{array}$ \\
\hline & Mixed forest & MF & $\begin{array}{l}\text { Interior of an intact patch of at least } 25 \% \text { broadleaved and } \\
25 \% \text { coniferous trees (in either upper or lower layer) } \\
\text { greater than } 4 \mathrm{~m} \text { in height. }\end{array}$ \\
\hline & Coniferous forest & $\mathrm{CF}$ & $\begin{array}{l}\text { Interior of an intact patch of predominantly coniferous trees } \\
\text { greater than } 4 \mathrm{~m} \text { in height. }\end{array}$ \\
\hline & Road through broadleaved forest & RtBF & $\begin{array}{l}\text { Dirt or paved road (with linear space, free of obstacles) walked } \\
\text { alongside through broadleaved forest. }\end{array}$ \\
\hline & Road through mixed forest & RtMF & $\begin{array}{l}\text { Dirt or paved road (with linear space, free of obstacles) walked } \\
\text { alongside through mixed forest }\end{array}$ \\
\hline & Road through coniferous forest & RtCF & $\begin{array}{l}\text { Dirt or paved road (with linear space, free of obstacles) walked } \\
\text { alongside through coniferous forest. }\end{array}$ \\
\hline & Clearing or young plantation (coniferous) & $\mathrm{CoPC}$ & $\begin{array}{l}\text { Areas of coniferous trees up to } 3 \mathrm{~m} \text { high, which had been planted } \\
\text { or areas inside coniferous forest, where there was evidence } \\
\text { that trees had been recently logged. }\end{array}$ \\
\hline & Clearing or young plantation (broadleaved) & $\mathrm{CoPB}$ & $\begin{array}{l}\text { Areas of broadleaved trees up to } 3 \mathrm{~m} \text { high, which had been planted } \\
\text { or areas inside broadleaved forest, where there was evidence } \\
\text { that trees had been recently logged. }\end{array}$ \\
\hline & Clearing or young plantation (mixed) & $\mathrm{CoPM}$ & $\begin{array}{l}\text { Areas of at least } 25 \% \text { broadleaved and } 25 \% \text { coniferous trees up } \\
\text { to } 3 \mathrm{~m} \text { high, which had been planted or areas inside mixed forest, } \\
\text { where there was evidence that trees had been recently logged. }\end{array}$ \\
\hline & Glade or permanent gap in broadleaved forest & GiBF & $\begin{array}{l}\text { Treeless area of less than } 30 \mathrm{~m} \text { in diameter/diagonal, located inside } \\
\text { deciduous forest, created by any other factor than logging and } \\
\text { not planted by young trees. }\end{array}$ \\
\hline & Glade or permanent gap in mixed forest & GiMF & $\begin{array}{l}\text { Treeless area of less than } 30 \mathrm{~m} \text { in diameter/diagonal, located inside } \\
\text { mixed forest, created by any other factor than logging and } \\
\text { not planted by young trees. }\end{array}$ \\
\hline & Glade or permanent gap in coniferous forest & $\mathrm{GiCF}$ & $\begin{array}{l}\text { Treeless area of less than } 30 \mathrm{~m} \text { in diameter/diagonal, located inside } \\
\text { coniferous forest, created by any other factor than logging and } \\
\text { not planted by young trees. }\end{array}$ \\
\hline & Broadleaved forest edge & $\mathrm{BFE}$ & $\begin{array}{l}\text { The edge of a deciduous woodland, walked alongside, which } \\
\text { bordered on another habitat type (excluding water or buildings). }\end{array}$ \\
\hline & Mixed forest edge & MFE & $\begin{array}{l}\text { The edge of a mixed woodland, walked alongside, which bordered } \\
\text { on another habitat type (excluding water or buildings). }\end{array}$ \\
\hline & Coniferous forest edge & $\mathrm{CFE}$ & $\begin{array}{l}\text { The edge of a coniferous woodland, walked alongside, which bordered } \\
\text { on another habitat type (excluding water or buildings). }\end{array}$ \\
\hline \multirow[t]{5}{*}{ Water or riparian } & Lake or pond & LoP & $\begin{array}{l}\text { Any inland patch of standing water, walked either alongside the shore } \\
\text { or crossed by a pier. }\end{array}$ \\
\hline & River or canal & $\mathrm{RoC}$ & $\begin{array}{l}\text { Any linear water body (usually running) of more than } 1 \mathrm{~m} \text { in width, } \\
\text { walked either alongside the bank or crossed by a bridge. }\end{array}$ \\
\hline & Reed or sedge bed & RoSB & $\begin{array}{l}\text { A patch of wetland with no open water surface, overgrown by intact, } \\
\text { dense Phragmites or Carex. }\end{array}$ \\
\hline & Sphagnum peat bog & SPB & $\begin{array}{l}\text { A patch of wetland with no open water surface, overgrown by mat } \\
\text { of Sphagnum peat moss. }\end{array}$ \\
\hline & Brackish lagoon & $\mathrm{Lg}$ & $\begin{array}{l}\text { Margin of brackish lagoon, overgrown by wide reedbed (far from } \\
\text { open water), bordered by forest. }\end{array}$ \\
\hline \multirow[t]{3}{*}{ Coastal (marine) } & Beach & $\mathrm{B}$ & $\begin{array}{l}\text { Stripe of flat sand at the sea coast, walked either alongside the } \\
\text { water or crossed. }\end{array}$ \\
\hline & Treeless dunes & $\mathrm{TD}$ & $\begin{array}{l}\text { Sand dunes at the sea coast, overgrown by sparse grasses, } \\
\text { sedges and low shrub. }\end{array}$ \\
\hline & Dunes with sparse trees & DwST & $\begin{array}{l}\text { Sand dunes at the sea coast, with } \sim 10-50 \% \text { of surface overgrown by } \\
\text { trees higher than } 4 \mathrm{~m} \text {, but not forming intact forest. }\end{array}$ \\
\hline Scrub & Broadleaved shrub & $\mathrm{BS}$ & $\begin{array}{l}\text { Area overgrown by broadleaved shrub (up to } 4 \mathrm{~m} \text { high) out of } \\
\text { any forest complex or settlement. }\end{array}$ \\
\hline
\end{tabular}


Table 1 (continued)

\begin{tabular}{|c|c|c|c|}
\hline Habitat group & Habitat class & Abbreviation & Definition \\
\hline & Mixed shrub & MS & $\begin{array}{l}\text { Area overgrown by at least } 25 \% \text { broad-leaved and } 25 \% \\
\text { coniferous shrubs (up to } 4 \mathrm{~m} \text { high) out of any forest } \\
\text { complex or settlement. }\end{array}$ \\
\hline & Coniferous shrub & $\mathrm{CS}$ & $\begin{array}{l}\text { Area overgrown by coniferous shrub (up to } 4 \mathrm{~m} \text { high) out } \\
\text { of any forest complex or settlement. }\end{array}$ \\
\hline \multirow[t]{2}{*}{ Open } & Arable land & $\mathrm{AL}$ & $\begin{array}{l}\text { Land outside settlements, used for growing any crop including rye, } \\
\text { barley, wheat, rapeseed, maize, beet, potatoes, cucumbers } \\
\text { or carrots (including fallows). }\end{array}$ \\
\hline & Meadow or pasture & MoP & $\begin{array}{l}\text { Grassland outside settlements used for hay production (mowed) } \\
\text { or livestock grazing. }\end{array}$ \\
\hline \multirow[t]{2}{*}{ Linear } & Tree line & $\mathrm{TL}$ & $\begin{array}{l}\text { Single or double line of trees (walked alongside), greater than } 4 \mathrm{~m} \\
\text { in height and less than three canopy across. Located in the } \\
\text { open area, outside settlements. }\end{array}$ \\
\hline & Hedgerow & $\mathrm{H}$ & $\begin{array}{l}\text { Line of shrub (walked alongside), less than } 4 \mathrm{~m} \text { in height and } 5 \mathrm{~m} \\
\text { width. Located in the open area, outside settlements. }\end{array}$ \\
\hline \multirow[t]{3}{*}{ Other green } & Gardens or orchards & GO & $\begin{array}{l}\text { Area used for growing vegetables, flowers or fruit, with at least } \\
50 \% \text { planted by fruit trees or bushes. }\end{array}$ \\
\hline & Park & $\mathrm{P}$ & $\begin{array}{l}\text { Intact area located in the settlement (greater than } 100 \mathrm{~m} \\
\text { in diagonal), planted with trees for recreational or ornamental } \\
\text { purposes, with no buildings. }\end{array}$ \\
\hline & Lawns & $\mathrm{L}$ & $\begin{array}{l}\text { Intact area located inside the settlement (greater than } 100 \mathrm{~m} \\
\text { in diagonal), overgrown by grass, with no buildings. }\end{array}$ \\
\hline \multirow[t]{3}{*}{ Settlement } & Village buildings & VB & $\begin{array}{l}\text { Intact settlements (less than } 2000 \text { inhabitants) with area } \\
\text { built-up by houses, barns and stables, areas built-up by } \\
\text { summer cottages, single farmsteads or forester's lodges } \\
\text { with adjacent buildings in the countryside. }\end{array}$ \\
\hline & Low suburb buildings & SB & $\begin{array}{l}\text { Usually peripheral, zones of large, intact settlements } \\
\text { (more than } 2500 \text { inhabitants) with predominantly } \\
\text { non-agricultural functions, built-up } \\
\text { with 1- or } 2 \text {-story houses. }\end{array}$ \\
\hline & High downtown buildings & $\mathrm{HCB}$ & $\begin{array}{l}\text { Central zones of large, intact settlements (more than } \\
2500 \text { inhabitants) with predominantly non-agricultural } \\
\text { functions, built-up with 3-6-story houses, public buildings, } \\
\text { stores, barracks and garages. }\end{array}$ \\
\hline
\end{tabular}

two calls (Thomas 1988; Rachwald 1992), separated from the next one by an interval ten times longer than the interval between the last two calls of the sequence, was taken as a single bat pass. Every pass was attributed to a particular UTM square, section of transect and habitat. Recorded sequences of echolocation calls were identified to the species level based on call type (FM, CF, QCF, FM-qcf, qcf-FM), frequency, call duration and interval length (Ahlén 1990; Vaughan et al. 1997b; Skiba 2003). All field recordings and bioacoustic analysis were conducted by one person, i.e. Mateusz Ciechanowski (in a similar way to Russ and Montgomery 2002). Both CD-ROMs with all bat recordings and maps with the original field drawings of the transects are stored in the archive of the Department of Vertebrate Ecology and Zoology, University of Gdańsk, Poland.

In many geographic regions, the application of ultrasound detection to studies on bat habitat use is strongly restricted by the strong similarity of echolocation calls among members of
Myotis genus. When dealing with the most European species of that genus, even application of discriminant function analysis (DFA) and artificial neural networks allows correct classification of only 50-70 \% Myotis bats (Vaughan et al. 1997b; Walters et al. 2012). This practically excludes its recognition in unknown areas if recording is not supported by visual observations of flight style and foraging tactics (Ahlén 1990); the latter is strictly dependent on the experience and subjective assessment of an expert. This problem, however, affects this study only to a minor extent. Intensive summer mist netting conducted in the Gdańsk Pomerania region revealed that more than $90 \%$ of Myotis bats captured belong to Daubenton's bat Myotis daubentonii (Ciechanowski 2002; Ciechanowski et al. 2002; Ciechanowski et al. 2007) and this allowed the assumption that most Myotis echolocation calls recorded there during the summer season are emitted by the same species. If possible, the presence of $M$. daubentonii was confirmed by either visual observation (i.e. of circling a few centimetres above the 
water surface-Ahlén 1990) or characteristic amplitude modulation, visible on oscillogram (Barataud 2012). The area is located out of the distribution range of Bechstein's bat Myotis bechsteinii, while whiskered bat M. mystacinus and Brandt's bat Myotis brandtii are known only from single records with no evidence of reproduction (Sachanowicz et al. 2006). Three other Myotis species are regularly recorded in the region; however, their identification based on spectral analysis of their calls is much easier: the greater mouse-eared bat Myotis myotis by its relatively low peak frequency $(\sim 30 \mathrm{kHz})$ and low repetition rate (e.g. Skiba 2003; Barataud 2012), Natterer's bat Myotis nattereri by its extremely broad frequency band (Dietz et al. 2009), the pond bat Myotis dasycneme by its lower frequency $(\sim 35 \mathrm{kHz})$ and occasional FM-cf-FM calls (Ahlén 1990; Skiba 2003). Cases of unambiguous identification of these three species were excluded from the 'Myotis sp.' group.

\section{Statistical analysis}

The number of recorded bat passes in particular habitat classes (their use) was compared with the proportion of that habitat in the total length of walked transects, i.e. their availability (Walsh and Harris 1996). Selection or avoidance of habitat categories was detected by constructing individual confidence intervals for each habitat using $\mathrm{Z}$ statistic with a Bonferroni adjustment. Confidence limits were set to $95 \%$ (thus $\alpha=0.05$ ) and compared with the expected proportion based on the availability of the habitat. If the expected value was within the confidence intervals, then I concluded that the habitat was used in proportion to its availability. If lower, then the habitat was selected, whereas if higher, then the habitat was avoided (Byers et al. 1984). Habitat classes where there was no bat activity (i.e. confidence limits could not be calculated) were excluded from the analysis. Breadth of habitat niche $(B)$ for every species was estimated using Levin's formula and niche overlaps $(O)$ between species using Pianka index (Posłuszny et al. 2007). Both indices were applied to the proportion of passes recorded in particular habitat classes.

\section{Results}

In total, 4063 bat passes (sequences of echolocation calls) were recorded; they belonged to at least 14 species (Table 2). The most numerous were the common pipistrelle $P$. pipistrellus, Nathusius' pipistrelle $P$. nathusii and common noctule $N$. noctula. The three other relatively common species were serotine Eptesicus serotinus and mostly unidentified representatives of Myotis genus (presumed to be Daubenton's bat M. daubentonii, confirmed visually in 91 cases) and soprano pipistrelle $P$. pygmaeus. These six taxa, each represented by more than 190 passes, were subjected to further analysis. Only 332 feeding buzzes (calls indicating attacks of bats on prey)
Table 2 The number and percentage of bat passes belonging to particular taxa

\begin{tabular}{lll}
\hline Taxon & Number & $\%$ \\
\hline Pipistrellus pipistrellus (Schreber 1774) & 828 & 20.4 \\
Pipistrellus nathusii (Keyserling and Blasius 1839) & 774 & 19.0 \\
Nyctalus noctula (Schreber 1774) & 703 & 17.3 \\
Eptesicus serotinus (Schreber 1774) & 566 & 13.9 \\
Myotis sp. (cf. daubentonii) (Kuhl 1817) & 553 & 13.6 \\
Pipistrellus pygmaeus (Leach 1825) & 198 & 4.9 \\
Pipistrellus sp. & 142 & 3.5 \\
Unidentified & 121 & 3.0 \\
Plecotus sp. & 45 & 1.1 \\
Nyctalus sp. & 38 & 0.9 \\
Nyctalus leisleri (Kuhl 1817) & 30 & 0.7 \\
Barbastella barbastellus (Kuhl 1817) & 15 & 0.4 \\
Eptesicus sp. & 16 & 0.4 \\
Myotis nattereri (Kuhl 1817) & 12 & 0.3 \\
Vespertilio murinus Linnaeus 1758 & 9 & 0.2 \\
Myotis dasycneme (Boie 1825) & 8 & 0.2 \\
Myotis myotis (Borkhausen 1797) & 3 & 0.1 \\
Eptesicus nilssonii (Keyserling and Blasius 1839) & 2 & 0.0 \\
Total & 4063 & 100.0 \\
\hline
\end{tabular}

were recorded, and their number was significantly correlated with the number of bat passes in particular UTM square (Spearman rank correlation, $r=0.57, N=69, p<0.0001$ ), and thus the analysis was conducted based solely on the number of passes.

The distribution of bat passes among habitat classes was strongly uneven, differing from the pattern expected based on their availability. Bats selected only lakes and ponds, rivers and canals, but they avoided mixed forests, coniferous forests, roads through coniferous forests, mixed forest edges, arable land, meadows and pastures, tree lines, hedgerows in the open areas and suburban buildings. The remaining habitats were used according to their availability, including most of the forest habitats (Fig. 2).

Particular bat species differed in habitat preferences. E. serotinus was revealed to be a synanthropic taxon, strongly selecting villages, as the only bat species to do so. It also selected roads through coniferous forests and treeless coastal dunes but avoided arable land, meadows and pastures, tree lines, roads through broadleaved forests and broadleaved forest edges. The remaining habitats were used by E. serotinus according to their availability; the serotine was the only species that did not select water bodies or riparian habitats (Fig. 3). The serotine was a eurytopic species $(B=9.06)$. $N$. noctula strongly selected only lakes and ponds, rivers and canals, and coastal lagoon. It avoided mixed forests, arable land, tree lines, hedgerows and roads through coniferous forests. Most habitat classes, even settlements, meadows and 


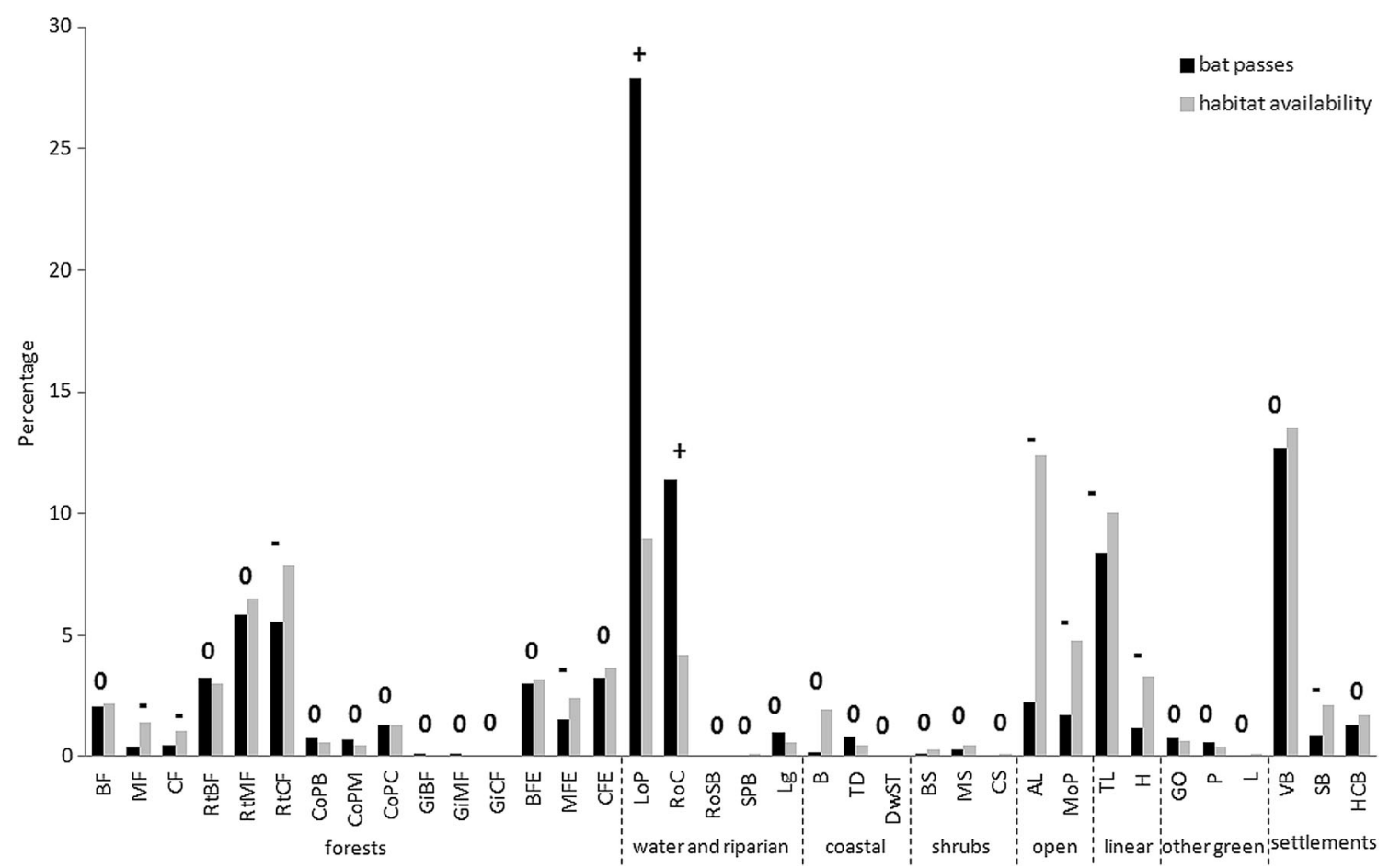

Fig. 2 Selection of habitats by all bat species. Habitat abbreviations are in Table 1. The number of passes recorded in particular habitat classes was compared with the expected number, recalculated from the

pastures, were used according to their availability (Fig. 4). The species was revealed to have the broadest habitat niche among the studied bats $(B=10.25)$.

All Pipistrellus species revealed much narrower habitat niches when compared to noctule and serotine. The most eurytopic species among them was $P$. pipistrellus $(B=7.86)$. It not only strongly selected - as the only bat species to do sotree lines but also preferred lakes and ponds, and rivers and canals. It avoided arable land, meadows and pastures, mixed and coniferous forests, roads through coniferous forests, and suburb buildings, but not villages (Fig. 5). The rarest member of the genus, $P$. pygmaeus, was revealed to occupy a slightly narrower niche $(B=6.64)$. It strongly selected lakes and ponds, and roads through broadleaved forests, but both rivers and canals, as well as villages, were used in proportion to their availability (Fig. 6). The second most frequent bat in the region, $P$. nathusii, occupied the narrowest habitat niche among pipistrelles $(B=5.24)$. It strongly selected only lakes, and rivers and canals, but avoided arable land, meadows and pastures, mixed forest edges, tree lines, hedgerows, villages and suburban buildings (Fig. 7). It used most forest habitats in proportion to their availability.

Myotis sp. (representing, presumably, M. daubentonii) preferred lakes and ponds, as well as rivers and canals but avoided mixed forests, roads through mixed and coniferous forests, broadleaved and coniferous forest edges, arable land, tree lines and villages (Fig. 8). It was the most stenotopic taxon among those analysed $(B=2.67)$. The remaining species availability of habitats on walked transects. Explanations: $(+)$ preferred, $(-)$ avoided and $(0)$ used in proportion to their availability

occurred too scarcely to allow any statistical analysis; however, it should be noted that 12 passes of barbastelle Barbastella barbastellus were recorded over the roads in mixed forests, one over the road in broadleaved forest, one at the clearing in mixed forest and one at the tree line crossing the open area. Among Natterer's bats $M$. nattereri, six passes were recorded over roads in mixed forests, three over the road in broadleaved forest, one at the coniferous forest edge, one on a small glade in a mixed forest and one at the tree line.

The majority of the studied species revealed strong overlaps in habitat niches (Pianka indices for species' pairs reached values $0.72-0.93$, mean 0.84$)$. The exception was E. serotinus, which revealed much lower niche overlaps with other species than any other taxon (mean $O=0.62$, range 0.38 0.76 , with $M$. daubentonii and $N$. noctula as respective extremes). Among morphologically similar Pipistrellus species, niche overlap between $P$. pygmaeus and $P$. nathusii was higher $(O=0.92)$ than between any of the two latter species and P. pipistrellus ( $O=0.78$ and $O=0.77$, respectively) (Table 3).

\section{Discussion}

Potential biases in the acoustic survey

Studies on habitat use by bats based on ultrasound detection provide several advantages when compared to the other methods, especially radiotracking. They allow to sample wide 


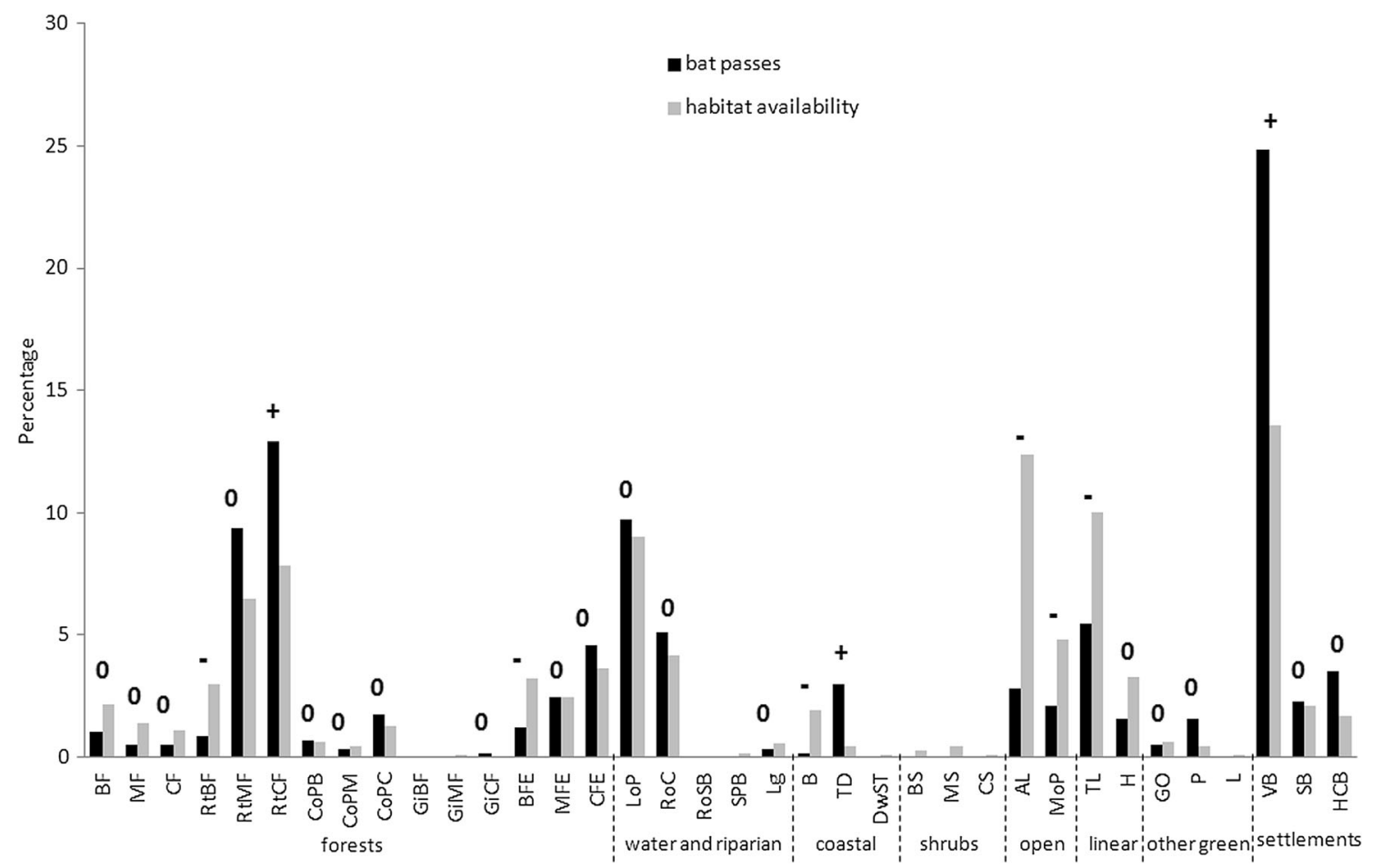

Fig. 3 Selection of habitats by Eptesicus serotinus. Habitat abbreviations are in Table 1. The number of passes recorded in particular habitat classes was compared with the expected number, recalculated from the

areas and several geographic locations at relatively low costs, collecting large number of records belonging to several species at the same time. These records cannot be, however, availability of habitats on walked transects. Explanations: $(+)$ preferred, $(-)$ avoided and (0) used in proportion to their availability

attributed to particular individuals, contrary to e.g. bearings obtained during radiotracking. Thus, it cannot be excluded that several passes are produced by one and the same

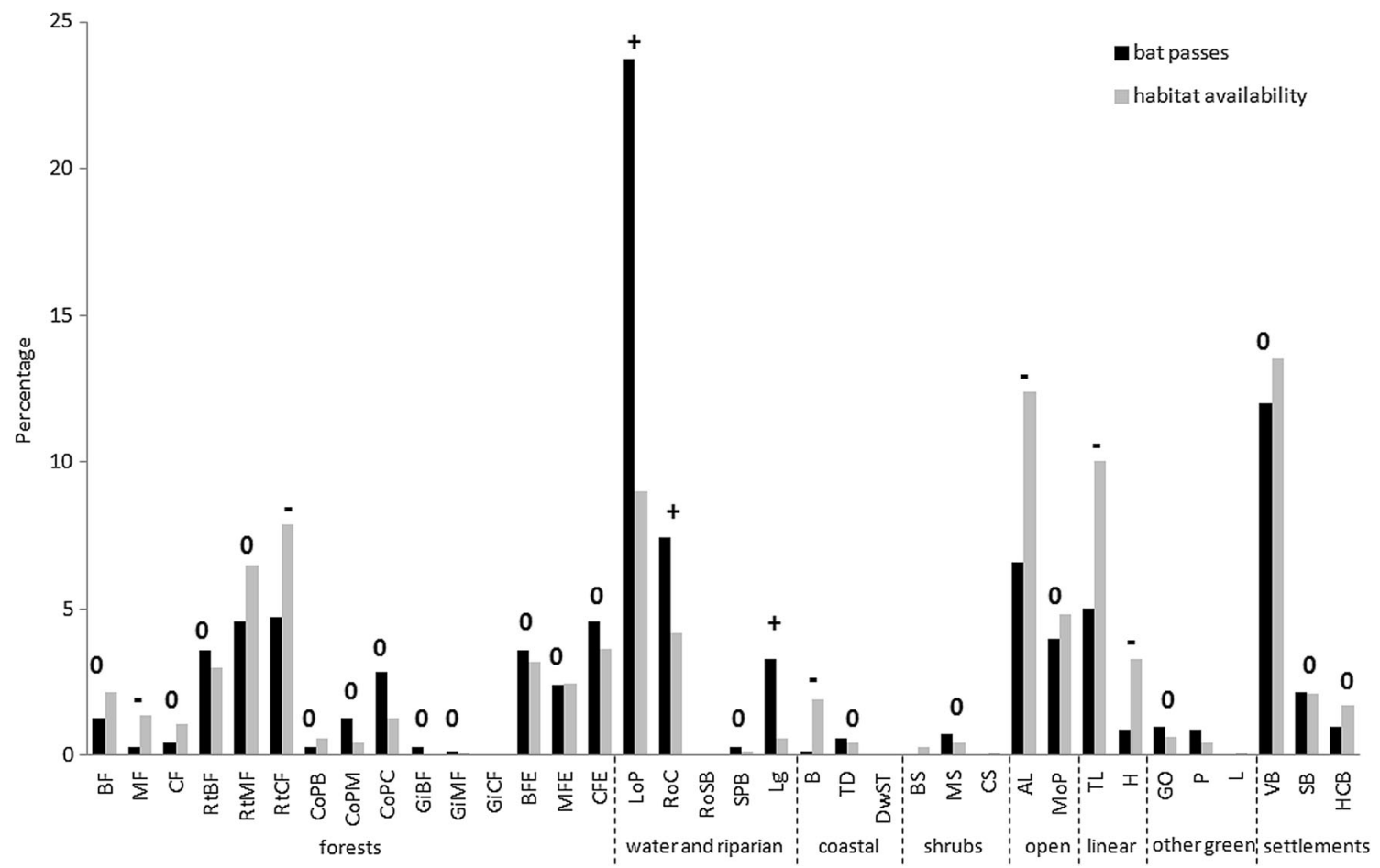

Fig. 4 Selection of habitats by Nyctalus noctula. Habitat abbreviations are in Table 1. The number of passes recorded in particular habitat classes was compared with the expected number, recalculated from the availability of habitats on walked transects. Explanations: $(+)$ preferred, $(-)$ avoided and $(0)$ used in proportion to their availability 


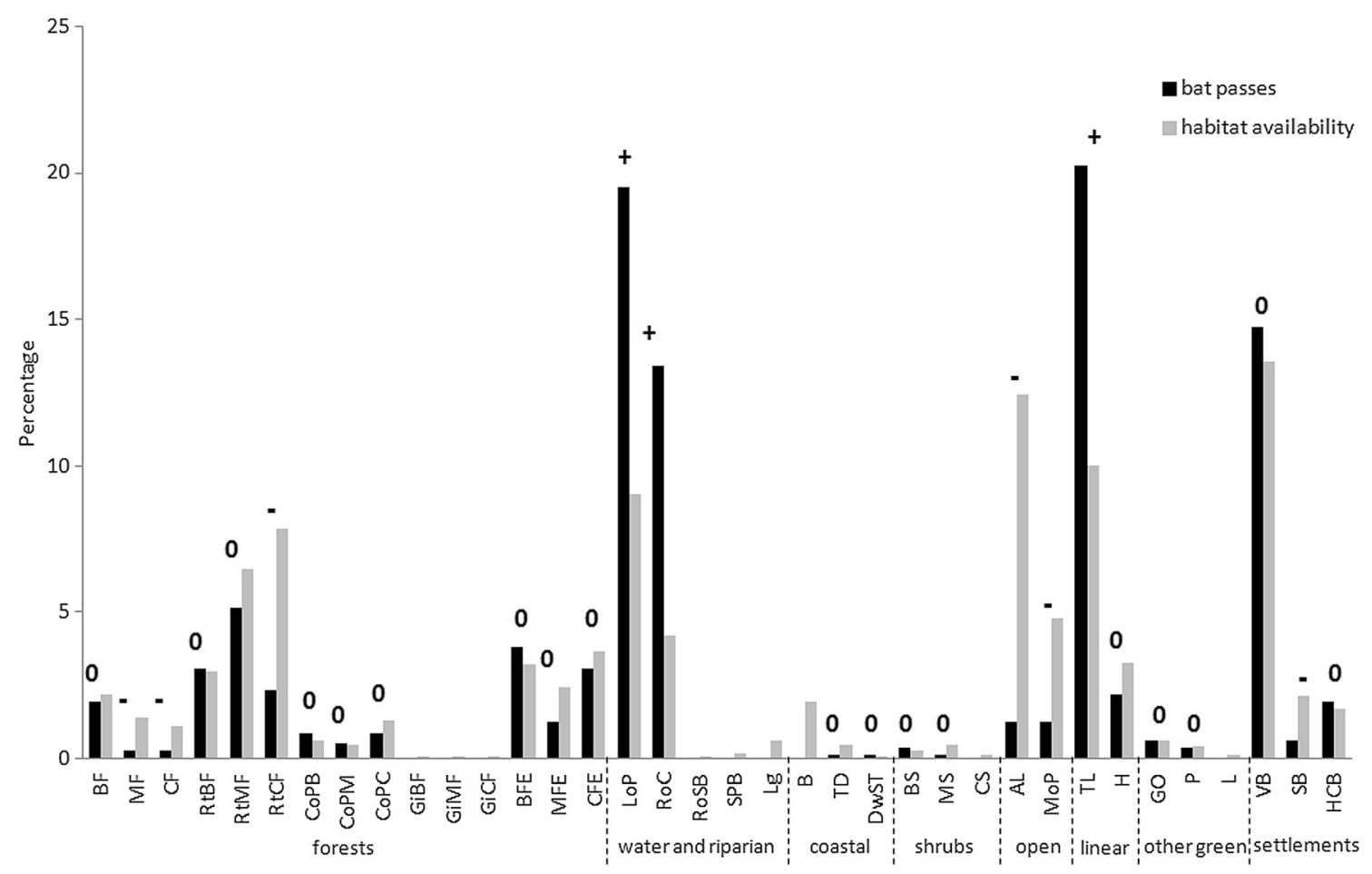

Fig. 5 Selection of habitats by Pipistrellus pipistrellus. Habitat abbreviations are in Table 1. The number of passes recorded in particular habitat classes was compared with the expected number,

individual that enters detection range of the microphone, resulting in unquantifiable pseudoreplication. The other limitation of method applied in this study is associated with the recalculated from the availability of habitats on walked transects. Explanations: $(+)$ preferred, $(-)$ avoided and (0) used in proportion to their availability

fact that sampling was restricted to 2 months; meanwhile, bat activity in Central Europe reveals strong seasonal variation (Ciechanowski et al. 2010). These 2 months coincide,

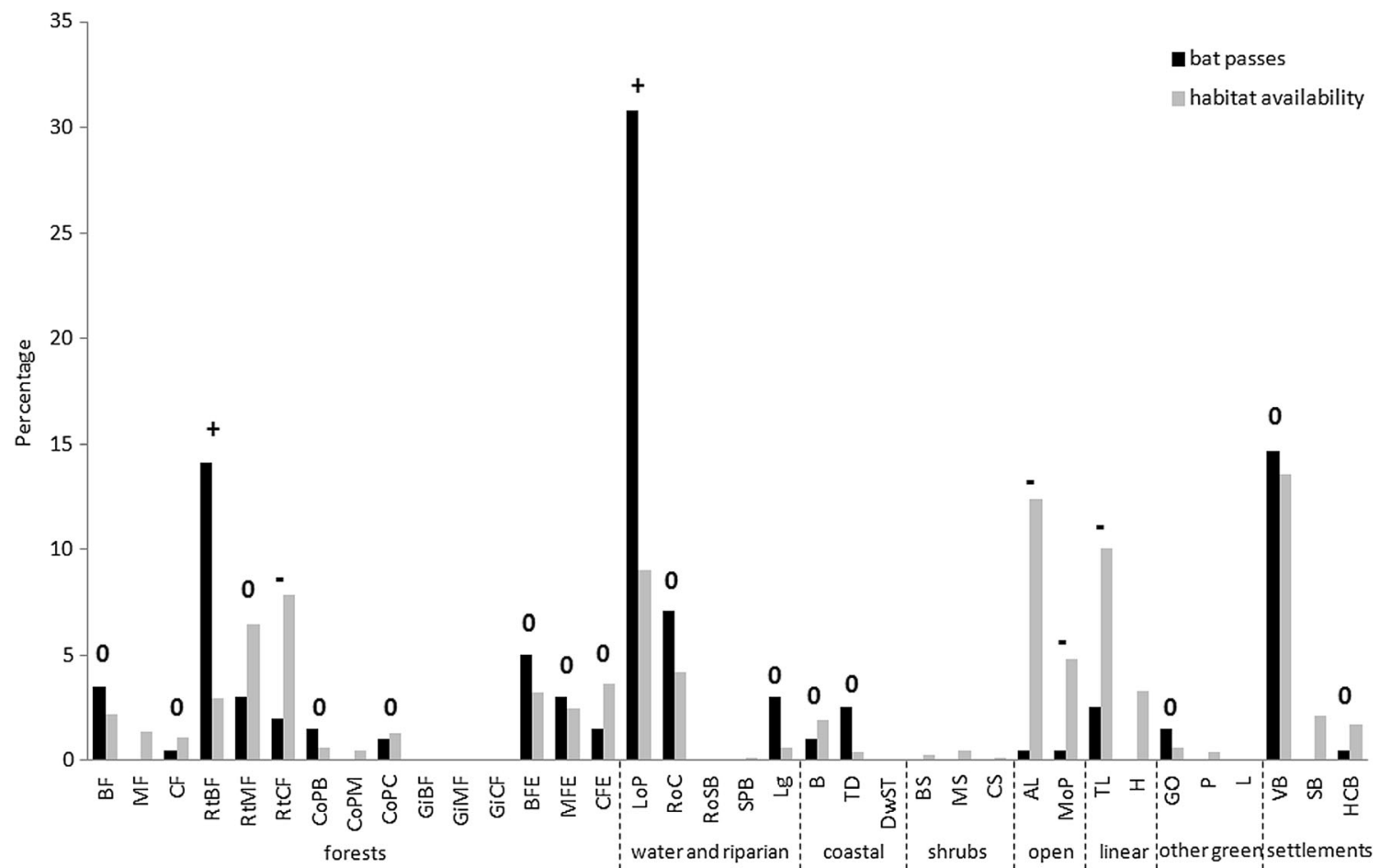

Fig. 6 Selection of habitats by Pipistrellus pygmaeus. Habitat abbreviations are in Table 1. The number of passes recorded in particular habitat classes was compared with the expected number, recalculated from the availability of habitats on walked transects. Explanations: $(+)$ preferred, $(-)$ avoided and $(0)$ used in proportion to their availability 


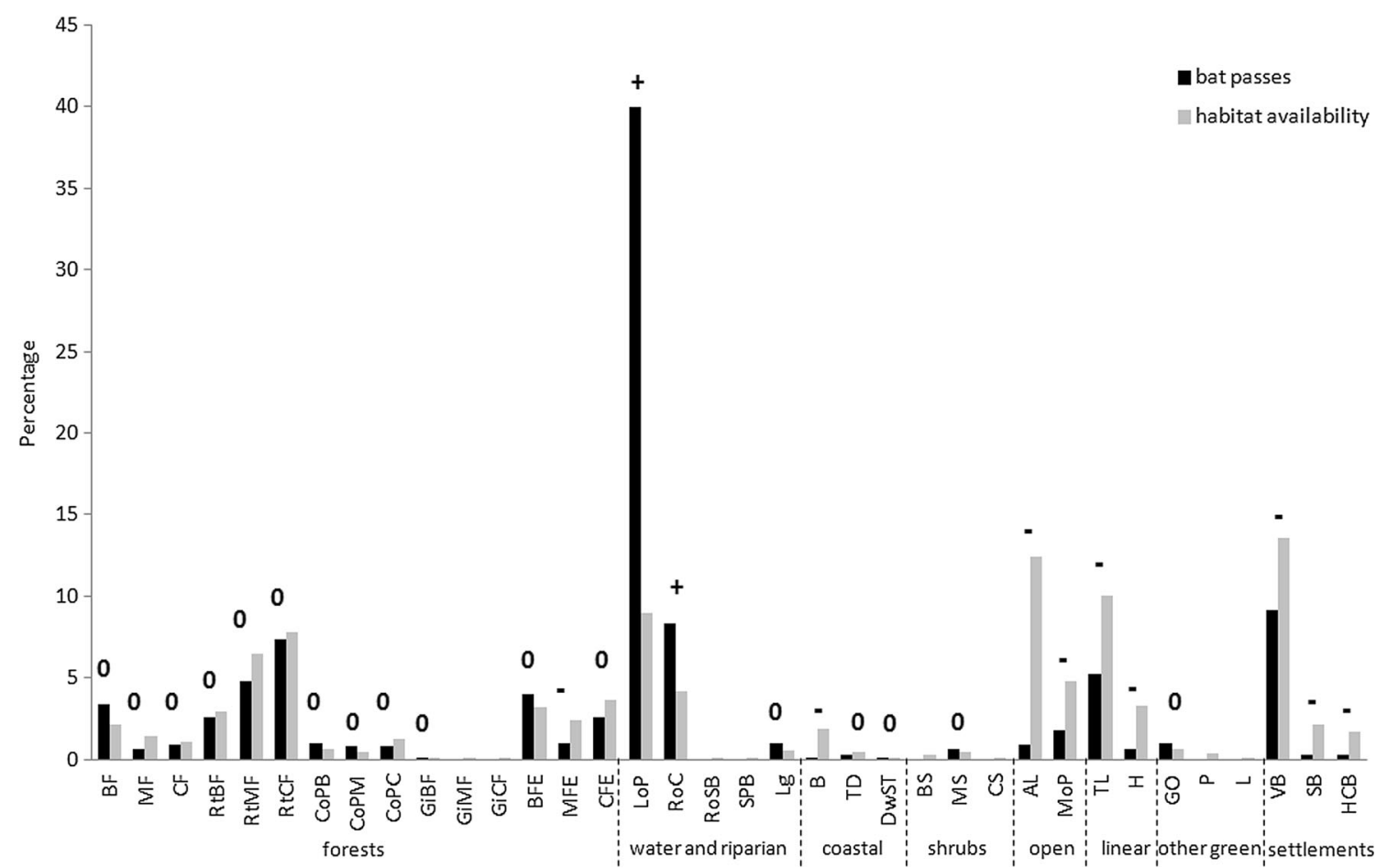

Fig. 7 Selection of habitats by Pipistrellus nathusii. Habitat abbreviations are in Table 1. The number of passes recorded in particular habitat classes was compared with the expected number,

however, with late pregnancy and the whole lactation, i.e. the period of the highest energy requirements for female bats (Studier et al. 1973), thus being crucial for maintaining their recalculated from the availability of habitats on walked transects. Explanations: $(+)$ preferred, $(-)$ avoided and $(0)$ used in proportion to their availability

stable populations and of the highest conservation importance. In some species, sexual differences in habitat use may occur (Safi et al. 2007), while during acoustic surveys, sexes cannot

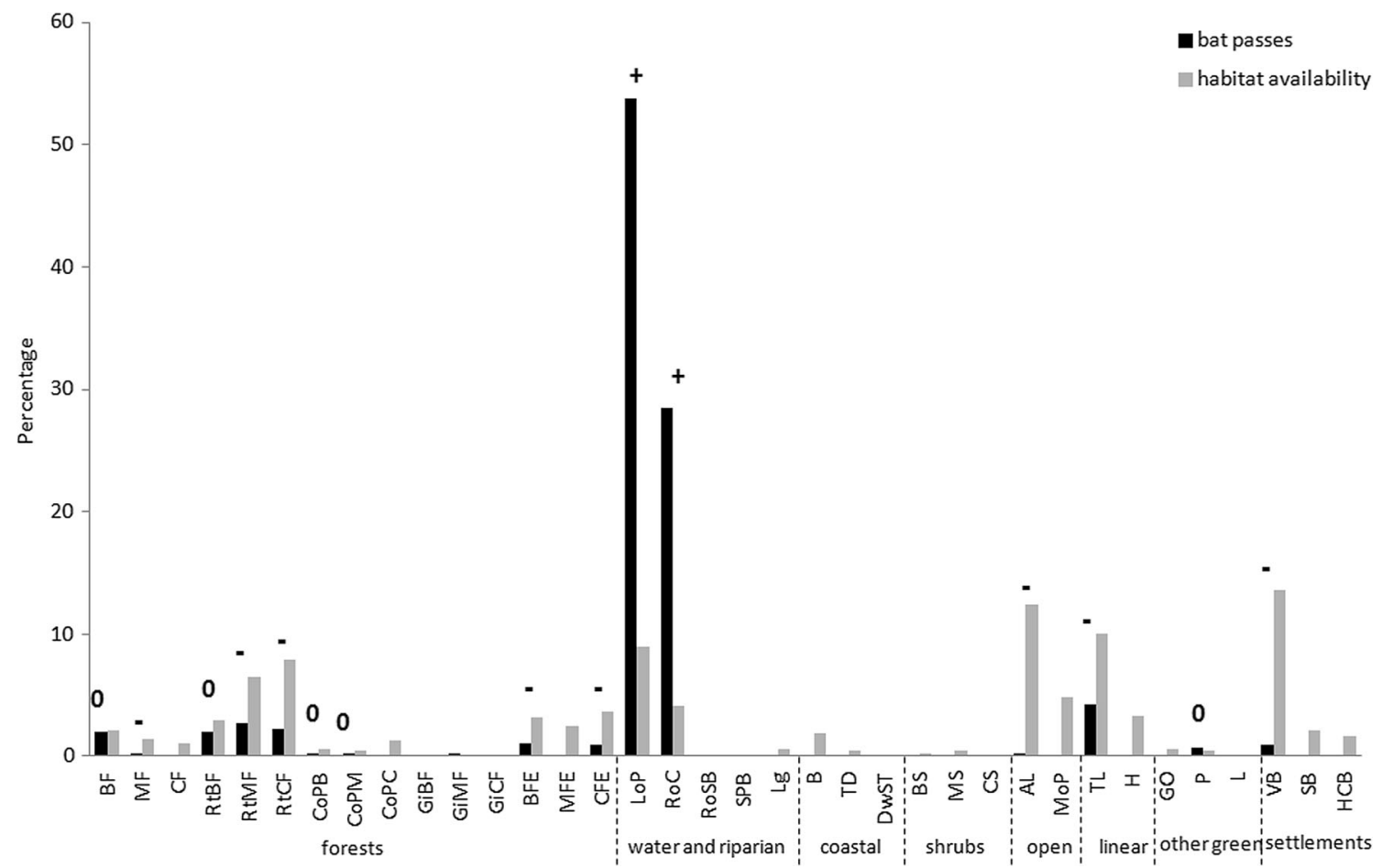

Fig. 8 Selection of habitats by Myotis species. Habitat abbreviations are in Table 1. The number of passes recorded in particular habitat classes was compared with the expected number, recalculated from the availability of habitats on walked transects. Explanations: $(+)$ preferred, $(-)$ avoided and $(0)$ used in proportion to their availability 
Table 3 Niche overlap between bat species, estimated by Pianka index, applied to percentage of passes recorded in particular habitats

\begin{tabular}{|c|c|c|c|c|c|c|}
\hline & E.serotinus & N.noctula & P.pipistrellus & P.pygmaeus & P.nathusii & Myotis sp. \\
\hline E. serotinus & - & 0.76 & 0.73 & 0.64 & 0.60 & 0.38 \\
\hline N. noctula & & - & 0.85 & 0.91 & 0.93 & 0.82 \\
\hline P. pipistrellus & & & - & 0.78 & 0.77 & 0.72 \\
\hline P. pygmaeus & & & & - & 0.92 & 0.82 \\
\hline P. nathusii & & & & & - & 0.92 \\
\hline
\end{tabular}

be distinguished and potential bias may occur, depending on the presence of female-dominated nursery roosts or male roosts in compared sites and habitats. Another bias might result from sampling only the first hours after sunset, as some bat species may shift from more shaded/cluttered to more open habitats during night (Lima and O'Keefe 2013). However, if application of the two successive walks of the transect allows to record the activity of species differing in timing of emergence in a comparable way (Warren et al. 2000), it is likely that it allows to control for also such temporal habitat shifts, as well.

General habitat preferences of bats in the study area

This study has revealed that in the postglacial landscapes of central Europe, the only habitats strongly selected by bats (treated as a group) are water bodies, both stagnant and running - they are the crucial resource and place of concentration in the landscape, used as either foraging habitat or as drinking sites (Ciechanowski 2002). Many other studies indicate the exceptional significance of water bodies and riparian habitats for bat fauna in the temperate zone of the Holarctic (e.g. Vaughan et al. 1997a; Menzel et al. 2005; Vindigni et al. 2009). It is usually associated with high abundance of flying insects, especially those undertaking their larval development in water (Fukui et al. 2006). The importance of water bodies for bats in lakelands of northern Poland appears to be higher than in Western Europe (Walsh and Harris 1996; Russ and Montgomery 2002), presumably due to much higher limnicity (Lehner and Döll 2004) and resulting greater availability of open water surface.

Contrary to the expectations, no clear selection of forests, including broadleaved ones, was disclosed; moreover, some habitat classes from the 'forest' group were even avoided. Large-scale studies usually reveal that bats prefer patches of landscape with higher forest cover, usually broadleaved but sometimes coniferous stands (Ekman and de Jong 1996; Walsh and Harris 1996; Russ and Montgomery 2002; Mehr et al. 2011). All these studies, however, do not distinguish between various habitats inside the forest patch at a local scale-between the interior of tree stands and canopy gaps or forest roads i.e. structures providing reduced clutter. Existing analyses taking into account microhabitats provide, however, contradictory results. Although Hein et al. (2009) found the probability of some species' occurrence several times greater where road was present in forest, another study found the probability of bat detection increasing with distance from the nearest road (Loeb and O'Keefe 2006). Forest edges are also considered preferred by foraging bats (Russ and Montgomery 2002; Cel'uch and Kropil 2008), although neither Vaughan et al. (1997a) nor this study reveal their exceptional importance.

The interior of intact, old-growth, multi-storey forests with closed canopy may provide a number of roosts (e.g. Kunz and Lumsden 2004) but not foraging habitats for the majority of bats. Thomas (1988) provided an evidence for that, recording a relatively high number of bat passes inside the old-growth stands but only during the first $15 \mathrm{~min}$ after sunset and with a very low number of feeding buzzes. Those species with very manouverable flight, e.g. foliage gleaners, might be the notable exception (Patriquin and Barclay 2003; Dietz et al. 2009); indeed, Myotis and Plecotus, representatives of that group, foraged mainly in stands with a high level of understorey vegetation (Jung et al. 2012). Also, in this study, some species were likely 'forest specialists' ( $M$. nattereri and B. barbastellus), but they represented a tiny proportion of all recorded bat passes.

Open areas - grasslands and arable lands — are considered to be strongly avoided by bats (Walsh and Harris 1996; Russ and Montgomery 2002); this fact has been confirmed in this study. It can be explained by neither prey availability nor constraints of spatial orientation, as at least, some bat species can easily cross the open habitats (e.g. Ekman and de Jong 1996). Avoidance of open areas by bats appears specific for pregnancy and lactation and cannot be extrapolated on seasonal, long-distance migrations of some species. In this period, bats regularly move even onto the open sea (Ahlén et al. 2009), so it is unlikely that they cannot cross large patches of arable land. Interestingly, in Pomerania, I did not record if bats as a group select tree lines in agricultural landscape (except P. pipistrellus, see below). Other studies stress that those habitats are strongly selected (Walsh and Harris 1996; Russ and Montgomery 2002) that is explained by their function as protection against wind and predators, and a high abundance of prey (Verboom and Spoelstra 1999). 
Habitat preferences of particular species

Habitat preferences of Myotis genus (strong selection of waters) might be explained by the predominance of one species, i.e. water-surface foraging specialist, $M$. daubentonii (Findley 1995; Dietz et al. 2009). Also, the other authors confirm that hunting $M$. daubentonii are recorded at water bodies and in their close neighbourhood (Vaughan et al. 1997a; Gaisler et al. 1998; Bartonička and Zukal 2003). M. nattereri, a foliage gleaner, appeared to be an example of a forest specialist, as its few passes were recorded at forest roads and glades, but the British radio tracking study revealed its preferences for the wooded, riparian corridors (Smith and Racey 2008).

E. serotinus is also indicated by some authors as the species preferring water bodies and riparian habitats (Lesiński et al. 2000; Bartonička and Zukal 2003). In England, however, it strongly selected pastures and woodlands (Robinson and Stebbings 1997) that was only partially confirmed in Pomerania by preference for roads in coniferous forests. The most distinct feature of habitat use by E. serotinus in this study is selection of villages and urban areas as main foraging/ commuting areas that might be explained by proximity to the species' daily roosts, i.e. almost exclusively buildings (Dietz et al. 2009), E. serotinus is the commonest bat in built-up areas of central Poland; its frequency of occurrence declines along the gradient of urbanization from the city centre to the countryside (Lesiński et al. 2000). Its preference for villages and use of waters only in proportion to their availability makes serotine an 'outlier' among the common bat species in the study area.

Noctule $N$. noctula reveals morphological and behavioural adaptations to foraging in open space and high above the ground (Baagøe 1987). In Poland, the majority of noctule's passes were recorded over the river valleys or riparian habitats and at the forest edges but rarely in agricultural landscape and only sporadically inside the intact forest (Rachwald 1992; Lesiński et al. 2000). In England, they foraged mostly over lakes and grasslands (Vaughan et al. 1997a) or selected pastures and forests while avoided arable lands and moorland (Mackie and Racey 2007). Selection of grasslands was not confirmed in this study; however, it was noticeable that $N$. noctula was the only species that did not avoid them. Finding fine-scale habitat relationships is not always possible in the case of that species, moving quickly among many different habitats and emitting echolocation calls easily detected even from a large distance (Barataud 2012). This results in the broadest habitat niche among Pomeranian bats and in lack of significant differences in activity among habitat classes in a local Czech study (Bartonička and Zukal 2003).

Co-occurring P. pipistrellus and P. pygmaeus may reveal partial - although subtle - separation of habitat niches (Nichols and Racey 2006). In south-western England, P. pygmaeus is more strongly associated with water bodies and riparian habitats in general, while $P$. pipistrellus uses a much broader habitat niche, also including arable land and villages (Vaughan et al. 1997a; Davidson-Watts et al. 2006). In Northern Ireland, P. pygmaeus was recorded mostly over waters and around broadleaved forests, while P. pipistrellus preferred rivers and tree lines (Russ and Montgomery 2002). These studies are confirmed by results from Pomerania, where both species prefer waters; however, P. pygmaeus is a stenotopic species that additionally selects roads in broadleaved forests and P. pipistrellus is a eurytopic species, common in agricultural landscape where it strongly selects tree lines that should be considered its crucial hunting habitat.

Available data about the habitat preferences of $P$. nathusii suggested that it appears much more rarely in habitats located far from water bodies, probably resulting in a much narrower niche than in the remaining members of the Pipistrellus genus. In south-western Germany, Gelhaus and Zahn (2010) found that $P$. nathusii preferred large lake, ponds and streams but avoided any woodland. Individuals radio tagged in the species' wintering areas in Spain foraged mostly over lagoons and marshes (Flaquer et al. 2009). However, in northern Germany, the majority of foraging P. nathusii were observed in humid broadleaved forests, while they avoided settlements and arable land, in contrast to the more synanthropic P. pipistrellus sensu lato (Jüdes 1989). This study confirms that $P$. nathusii-although widespread-is, in similarity to $M$. daubentonii, a stenotopic species, specialized in the use of water bodies (confirmed by diet, dominated by Chironomidae - Vaughan 1997) while avoiding anthropogenic landscapes.

Niche overlap and resource partitioning

The strong overlap of the habitat niches of the most numerous bat species (water bodies selected in five out of six cases) may induce questions about the significance of interspecific competition in the organization of bat assemblage. Part of that species, however, use different hunting tactics (Findley 1995) and forage in different microhabitats, defined by height above the ground or water surface and distance from vegetation (Baagøe 1987). The only group that might be expected to compete for food are morphologically similar species of Pipistrellus. However, some earlier studies on differences in habitat use (Vaughan et al. 1997a; Davidson-Watts et al. 2006) between P. pipistrellus and P. pygmaeus do not resemble the typical pattern of resource partitioning, usually recorded for sibling species in sympatry. They indicated rather more eurytopic habits in P. pipistrellus and some specialization in $P$. pygmaeus, but the most preferred habitats are almost the same. In Switzerland, stenotopic P. pygmaeus uses a much narrower habitat niche than eurytopic $P$. pipistrellus but completely overlaps with the niche of the latter (Sattler et al. 2007). On the contrary, a principal component analysis, performed by Nichols and Racey (2006) on the proportion of 
time spent in each habitat, showed a distinct clustering of radiotracked individuals of the two species, with no overlap, providing clear evidence for habitat partitioning.

Resource partitioning between P. pipistrellus and the remaining two Pipistrellus species may be based on partial differences in habitat preferences; however, the strong overlap in habitat niche between P. nathusii and P. pygmaeus is astonishing. In the latter case, habitat partitioning may result from large differences in body size (Dietz et al. 2009: fifth finger length $P$. nathusii $41-48 \mathrm{~mm}$ and $P$. pygmaeus $33-40 \mathrm{~mm}$ ) and in the frequency of echolocation calls (Skiba 2003: peak frequency $P$. nathusii $37-41 \mathrm{kHz}$ and $P$. pygmaeus $50-60 \mathrm{kHz}$ ) that may indeed drive differences in the size of their prey (P. pipistrellus occupies intermediate values between the last two taxa, fifth finger 37-41 mm, peak frequency of the signals $42-51 \mathrm{kHz})$. Greater similarity in the forest microhabitat preferences between the largest and the smallest Pipistrellus species, than between them and their intermediate congeneric, was reported also by Jung et al. (2012). Distribution modelling, performed by Kusch and Schmitz (2013), revealed stronger habitat specialization in $P$. nathusii and P. pygmaeus, compared to more generalist $P$. pipistrellus, providing additional evidence for greater ecological similarity between the first two species.

\section{Recommendations for bat conservation}

The results can help to include bat needs in landscape planning in a way adapted to the regional ecological context. The efforts undertaken to provide foraging and commuting habitats for bats in central European lakeland zones-if expected to be cost-effective - should focus on maintaining continuity of wooded stripes and riparian vegetation along lakeshores and river banks (e.g. Warren et al. 2000) and keeping good water quality (Biscardi et al. 2007), i.e. protecting lakes and rivers from anthropogenic pollution. Terrestrial habitats during pregnancy and lactation require less attention. The exception is tree lines in farmland areas, recently threatened by modernization of local roads. Their continuity must be preserved and their felling minimized if the most common bat species in the agroecosystems, P. pipistrellus, still has to provide its presumed ecosystem services (pest insect control). On the contrary, management of woodlands for bats in the studied region should focus on conservation of their daily roosts and does not require special modifications for maintenance of foraging sites. The latter recommendation should not be extended to threatened forest specialists (M. bechsteinii and B. barbastellus —Dietz et al. 2009), and the radiotracking is needed to establish their habitat preferences.

Acknowledgments The author is cordially thankful to Marta Więckowska for conducting the transect measurements in GIS software, helping with the preparation of figures and field works in 2010. The study was supported by a grant from the Ministry of Science and Higher
Education, Republic of Poland no. N N304 131036, and a grant of the University of Gdańsk, BW1440-5-0369-8.

All applicable international, national and/or institutional guidelines for the care and use of animals were followed.

Open Access This article is distributed under the terms of the Creative Commons Attribution License which permits any use, distribution, and reproduction in any medium, provided the original author(s) and the source are credited.

\section{References}

Ahlén I (1990) Identification of bats in flight. Swedish Society for Conservation of Nature and The Swedish Youth Association for Environmental Studies and Conservation, Stockholm

Ahlén I, Baagøe HJ, Bach L (2009) Behaviour of Scandinavian bats during migration and foraging at sea. J Mammal 90:1318-1323

Baagøe HJ (1987) The Scandinavian bat fauna: adaptive wing morphology, and free flight in the field. In: Fenton MB, Racey PA, Rayner JMV (eds) Recent advances in the study of bats. Cambridge University Press, Cambridge, pp 57-74

Barataud M (2012) Écologie acoustique des chiroptères d'Europe. Biotope - Muséum national d'Histoire naturelle, Méze and Paris

Bartonička T, Zukal J (2003) Flight activity and habitat use of four bat species in a small town revealed by bat detectors. Folia Zool 52: $155-166$

Biscardi S, Russo D, Casciani V, Cesarini D, Mei M, Boitani L (2007) Foraging requirements of the endangered long-fingered bat: the influence of micro-habitat structure, water quality and prey type. J Zool 273:372-381

Byers R, Steinhorst RK, Krausman PR (1984) Clarification of a technique for analysis of utilization-availability data. J Wildl Manag 48:1050 1053

Cel'uch M, Kropil R (2008) Bats in a Carpathian beech-oak forest (Central Europe): habitat use, foraging assemblages and activity patterns. Folia Zool 57:358-372

Ciechanowski M (2002) Community structure and activity of bats (Chiroptera) over different water bodies. Mamm Biol 67:276-285

Ciechanowski M, Koziróg L, Duriasz J, Przesmycka A, Świątkowska A, Kisicka I, Kasprzyk K (2002) Bat fauna of the Iława Lakeland Landscape Park (northern Poland). Myotis 40:33-45

Ciechanowski M, Zając T, Biłas A, Dunajski R (2007) Spatiotemporal variation in activity of bat species differing in hunting tactics: effects of weather, moonlight, food abundance, and structural clutter. Can J Zool 85:1249-1263

Ciechanowski M, Zając T, Biłas A, Dunajski R (2010) Seasonal activity patterns of seven vespertilionid bat species in Polish lowland. Acta Theriol 55:301-314

Davidson-Watts I, Walls S, Jones G (2006) Differential habitat selection by Pipistrellus pipistrellus and Pipistrellus pygmaeus identifies distinct conservation needs for cryptic species of echolocating bats. Biol Conserv 133:118-127

Dietz C, Helversen O, Nill D (2009) Bats of Britain. Europe and Northeastern Africa A\&C Black, London

Ekman M, de Jong J (1996) Local patterns of distribution and resource utilization of four species (Myotis brandti, Eptesicus nilssoni, Plecotus auritus and Pipistrellus pipistrellus) in patchy and continuous environments. J Zool 238:571-580

Findley J (1995) Bats. A community perspective. Cambridge Studies in Ecology. Cambridge University Press, Cambridge, United Kingdom $1: 1-167$ 
Flaquer C, Puig-Montserrat X, Goiti U, Vidal F, Curcó A, Russo D (2009) Habitat selection in Nathusius' pipistrelle (Pipistrellus nathusii): the importance of wetlands. Acta Chiropterol 11:149-155

Fukui D, Murakami M, Nakano S, Aoi T (2006) Effect of emergent aquatic insects on bat foraging in a riparian forest. J Anim Ecol 75:1252-1258

Gaisler J, Zukal J, Řehák Z, Homolka M (1998) Habitat preferences and flight activity of bats in a city. J Zool 244:439-445

Gelhaus M, Zahn A (2010) Roosting ecology, phenology and foraging habitats of a nursery colony of Pipistrellus nathusii in the southwestern part of its reproduction range. Vespertilio 13-14:93-102

Hein CD, Catleberry SB, Miller KV (2009) Site-occupancy of bats in relation to forest corridors. For Ecol Manag 257:1200-1207

Jones G (1995) Flight performance, echolocation and foraging behavior in noctule bat Nyctalus noctula. J Zool 237:303-312

Jüdes U (1989) Analysis of the distribution of flying bats along linetransects. In: Hanák V, Horaček I, Gaisler J (eds) European bat research 1987. Charles University Press, Praha, pp 311-318

Jung K, Kaiser S, Böhm S, Nieschulze J, Kalko EKV (2012) Moving in three dimensions: effects of structural complexity on occurrence and activity of insectivorous bats in managed forest stands. J Appl Ecol 49:523-531

Kunz TH, Lumsden LF (2004) Ecology of cavity and foliage roosting bats. In: Kunz T, Fenton MB (eds) Bat ecology. The University of Chicago Press, Chicago and London, pp. 3-89

Kusch J, Schmitz A (2013) Environmental factors affecting the differential use of foraging habitat by three sympatric species of Pipistrellus. Acta Chiropterol 15(1):57-67

Lehner B, Döll P (2004) Development and validation of a global database of lakes, reservoirs and wetlands. J Hydrol 296:1-22

Lesiński G, Fuszara E, Kowalski M (2000) Foraging areas and relative density of bats (Chiroptera) in differently human transformed landscapes. Z Säugetierkd 65:129-137

Lima S, O'Keefe JM (2013) Do predators influence the behaviour of bats? Biol Rev 88:626-644

Loeb SC, O'Keefe JM (2006) Habitat use by forest bats in South Carolina in relation to local, stand, and landscape characteristics. Wildl Manage 70:1210-1218

Mackie I, Racey PA (2007) Habitat use varies with reproductive state in noctule bats (Nyctalus noctula): implications for conservation. Biol Conserv 140:70-77

Markowski R, Buliński M (2004) Endangered and threatened vascular plants of Gdańskie Pomerania. Acta Bot Cassubica Monogr 1:5-75 (in Polish with English summary)

Mehr M, Brandl R, Horthorn T, Dziock F, Förster B, Müller J (2011) Land use is more important than climate for species richness and composition of bat assemblages on a regional scale. Mamm Biol 76: 451-460

Menzel JM, Menzel MA, Kilgo JC, Ford WM, Edwards JW, McCracken GF (2005) Effect of habitat and foraging height on bat activity in the costal plain of South Carolina. J Wildl Manage 69: 235-245

Nichols B, Racey PA (2006) Habitat selection as a mechanism of resource partitioning in two cryptic bat species Pipistrellus pipistrellus and Pipistrellus pygmaeus. Ecography 29:697-708

Patriquin KJ, Barclay RMR (2003) Foraging by bats in cleared, thinned and unharvested boreal forest. J Appl Ecol 40:646-657

Posłuszny M, Pilot M, Goszczyński J, Gralak B (2007) Diet of sympatric pine marten (Martes martes) and stone marten (Martes foina) identified by genotyping of DNA from faeces. Ann Zool Fenn 44:269284

Rachwald A (1992) Habitat preference and activity of the noctule bat Nyctalus noctula in the Białowieża Primeval Forest. Acta Theriol $37: 413-422$
Robinson MF, Stebbings RE (1997) Home range and habitat use by the serotine bat, Eptesicus serotinus, in England. J Zool 243:117-136

Russ JM, Montgomery WI (2002) Habitat associations of bats in Northern Ireland: implications for conservation. Biol Conserv 108: 49-58

Rydell J, Petersons G (1998) The diet of the Noctule bat Nyctalus noctula in Latvia. Z Saugetierkd 63:79-83

Sachanowicz K, Ciechanowski M, Piksa K (2006) Distribution patterns, species richness and status of bats in Poland. Vespertilio 9-10:151173

Safi K, König B, Kerth G (2007) Sex differences in population genetics, home range size and habitat use of the parti-colored bat (Vespertilio murinus, Linnaeus 1758) in Switzerland and their consequences for conservation. Biol Conserv 137:28-36

Sanderson EW, Redford KH, Chetkiewitz CB, Medellin RA, Rabinowitz AR, Robinson JG, Taber AB (2002) Planning to save a species: the jaguar as a model. Conserv Biol 16:58-72

Sattler T, Bontadina F, Hirzel AH, Arlettaz R (2007) Ecological niche modelling of two cryptic bat species calls for a reassessment of their conservation status. J Appl Ecol 44:1188-1199

Skiba R (2003) Europäische Fledermäuse. Die Neue Brehm Bücherei Band 648. Westarp Wissenschaften, Hochenwarsleben

Smith PG, Racey PA (2008) Natterer's bats prefer foraging in broadleaved woodlands and river corridors. J Zool 275:314-322

Studier EH, Lysengen VL, O'Farrell MJ (1973) Biology of Myotis thysanodes and M. lucifugus (Chiroptera: Vespertilionidae)-II. Bioenergetics of pregnancy and lactation. Comp Biochem Physiol 44A:467-471

Thomas DW (1988) The distribution of bats in different ages of Douglasfir forest. J Wildl Manag 52:619-626

Threfall CG, Law B, Banks PB (2012a) Influence of landscape structure and human modifications on insect biomass and bat foraging activity in an urban landscape. PLoS One 7:e38800. doi:10.1371/journal. pone. 0038800

Threfall CG, Law B, Banks PB (2012b) Sensitivity of insectivorous bats to urbanization: implications for suburban conservation planning. Biol Conserv 146:41-52

Vaughan N (1997) The diets of British bats (Chiroptera). Mammal Rev 27:77-94

Vaughan N, Jones G, Harris S (1997a) Habitat use by bats (Chiroptera) assessed by means of a broad-band acoustic method. J Appl Ecol 34: 716-730

Vaughan N, Jones G, Harris S (1997b) Identification of British bat species by multivariate analysis of echolocation call parameters. Bioacoustics 7:189-207

Verboom B, Huitema H (1997) The importance of linear landscape elements for the pipistrelle Pipistrellus pipistrellus and the serotine bat Eptesicus serotinus. Landsc Ecol 12:117-125

Verboom B, Spoelstra K (1999) Effects of food abundance and wind on the use of tree lines by an insectivorous bat, Pipistrellus pipistrellus. Can J Zool 77:1393-1401

Vindigni MA, Morris AD, Miller DA, Kalcounis-Rueppell MC (2009) Use of modified water sources by bats in a managed pine landscape. For Ecol Manag 258:2056-2061

Walsh AL, Harris S (1996) Foraging habitat preferences of vespertilionid bats in Britain. J Appl Ecol 33:508-518

Walters CL, Freeman R, Collen A, Dietz C, Brock Fenton M, Jones G, Obrist MK, Puechmaille SJ, Sattler T, Siemers BM, Parsons S, Jones KE (2012) A continental-scale tool for acoustic identification of European bats. J Appl Ecol 49:1064-1074

Warren R, Waters D, Altringham J, Bullock D (2000) The distribution of Daubenton's bats (Myotis daubentonii) and pipistrelle bats (Pipistrellus pipistrellus) (Vespertilionidae) in relation to smallscale variation in riverine habitat. Biol Conserv 92:85-91 